\title{
Management of Drug-induced Weight Gain in Persons Receiving Psychotropic Drugs
}

\author{
Vikas Menon ${ }^{1}$, Samir K Praharaj ${ }^{2}$
}

\begin{abstract}
Weight gain is common in patients with severe mental illness and contributes to cardiovascular risk. Medications, such as antipsychotics, antidepressants, and mood stabilizers, are commonly associated with weight gain. In addition, antidiabetic drugs (insulin, sulfonylureas, and thiazolidinediones), antihypertensives (beta-blockers), and corticosteroids, which are commonly used to treat comorbid medical conditions, contribute to weight gain. In clinical practice, simple measures, such as body weight, body mass index, and waist circumference, can be used to monitor the metabolic risk of psychotropic drugs. Lifestyle modifications, including dietary advice and exercise, help in preventing weight gain. The clinician can choose relatively weight-neutral drugs for the treatment of psychiatric disorders. For the patients having weight gain with psychotropic drugs, several nonpharmacological and pharmacological management strategies are available.

Keywords: Metabolic syndrome, Obesity, Psychotropic drugs, Severe mental illness, Weight gain.

Indian Journal of Private Psychiatry (2021): 10.5005/jp-journals-10067-0071
\end{abstract}

\section{INTRODUCTION}

Patients with severe mental illness (SMI) experience a life span that is 15-20 years shorter compared to the general population. ${ }^{1,2}$ Physical conditions are a major contributor to the increased risk of mortality observed in SMI. In particular, cardiovascular diseases (CVD) account for 17.4 and $22.0 \%$ of reduced life expectancy in men and women, respectively; these figures surpass the contribution of suicide, which is pegged at $13.5 \% .^{3}$ Among the major contributors to an increased prevalence of CVD in SMI patients are the increased prevalence of CVD-related risk factors, such as obesity, dyslipidemia, and diabetes mellitus. ${ }^{4}$ These may aggravate the risk of CVD when co-occurring with genetic predispositions and behavioral factors, such as sedentary lifestyle, unhealthy food choices, and smoking.

Compounding matters further are the adverse effects of drugs, such as antipsychotics, used to treat SMl; these include weight gain, dyslipidemia, and abnormalities in glucose metabolism. The term metabolic syndrome denotes a clustering of these multiple, concurrent risk factors for CVD in an individual; the rates of metabolic syndrome in schizophrenia and bipolar disorders were $32.5^{5}$ and $37.3 \%$, ${ }^{6}$ respectively. Further, the prevalence of metabolic syndrome among antipsychotic-naïve and antipsychotic-treated patients with schizophrenia was estimated between $3.3-26 \%$ and 32-68\%.

Obesity, a component of metabolic syndrome, is defined by the World Health Organization as "excessive body fat accumulation that is associated with clear risks to health." The measures to describe obesity are body weight and Quetelet index or body mass index (BMI); males with body weight more than $35 \%$ (in females, it is $45 \%$ ) or BMI more than $30 \mathrm{~kg} / \mathrm{m}^{2}$ are considered obese. The percentage of body fat for given BMI changes with age in a curvilinear fashion; hence BMI underestimates obesity. ${ }^{8,9}$ Also, Indians have more body fat for a given BMI, thus making BMI cutoffs unreliable. The Indian Consensus Group suggested a cutoff BMI of $25 \mathrm{~kg} / \mathrm{m}^{2}$ for defining obesity among Asian Indians residing in India. ${ }^{10}$

The other proxy measures for obesity, specifically abdominal obesity, are waist circumference (WC) and waist-hip ratio (WHR)
${ }^{1}$ Department of Psychiatry, Jawaharlal Institute of Postgraduate Medical Education and Research, Puducherry, India

2Department of Psychiatry, Kasturba Medical College, Manipal, Manipal Academy of Higher Education, Manipal, Karnataka, India

Corresponding Author: Samir K Praharaj, Department of Psychiatry, Kasturba Medical College, Manipal, Manipal Academy of Higher Education, Manipal, Karnataka, India, Phone: +91 8971026304, e-mail: samirpsyche@yahoo.co.in

How to cite this article: Menon V, Praharaj SK. Management of Drug-induced Weight Gain in Persons Receiving Psychotropic Drugs. Ind J Priv Psychiatry 2021;15(1):10-16.

Source of support: Nil

Conflict of interest: None

(Table 1). The WC cutoffs for high risk are $102 \mathrm{~cm}$ in men and $88 \mathrm{~cm}$ in women. ${ }^{11}$ However, separate cutoffs are suggested for Asians (including Indians), with above $90 \mathrm{~cm}$ in males and $80 \mathrm{~cm}$ in females considered as high risk. WHR reflects the fat distribution of lower and upper body areas; android type of excess upper body fat is typical of males, and gynoid type of excess lower body fat is more common among females. WHR cutoffs for risk are 1 for men and 0.85 for women. ${ }^{11}$ It is less useful as a measure of abdominal obesity with increasing levels of fat. Several other measures, including skinfold measurements, bioelectrical impedance analysis, hydrodensitometry, air-displacement plethysmography, dualenergy X-ray absorptiometry, and other imaging modalities, have been used for the obesity assessment in research. ${ }^{12}$ The computed tomography and magnetic resonance imaging of body parts are more accurate methods to measure visceral obesity. ${ }^{13}$

Prior reviews on drug-induced weight gain in patients with SMI have either focused on generating estimates for the risk of weight gain with different psychotropic agents, ${ }^{14}$ was not focused on management aspects, ${ }^{15}$ or had a narrow focus on pharmacological management strategies. ${ }^{16}$ Instead, we have focused our review on the management that describes practical aspects of pharmacological and nonpharmacological 
Table 1: Standard assessment of obesity

\begin{tabular}{|c|c|c|c|}
\hline & Measure & Definition & Interpretation \\
\hline 1 & Body weight & $\begin{array}{l}\text { Difference from ideal } \\
\text { body weight }\end{array}$ & $\begin{array}{l}>35 \% \text { in males and } \\
45 \% \text { in females }\end{array}$ \\
\hline 2 & $\begin{array}{l}\text { Body mass } \\
\text { index }\end{array}$ & $\begin{array}{l}\text { Ratio of body weight } \\
\text { in } \mathrm{kg} \text { and surface area } \\
\text { in } \mathrm{m}^{2}\end{array}$ & $\begin{array}{l}>30 \mathrm{~kg} / \mathrm{m}^{2}\left(25 \mathrm{~kg} / \mathrm{m}^{2}\right. \\
\text { in Asians) is obesity }\end{array}$ \\
\hline 3 & $\begin{array}{l}\text { Waist } \\
\text { circumference }\end{array}$ & $\begin{array}{l}\text { Measured at the end of } \\
\text { expiration in a standing } \\
\text { position at the midpoint } \\
\text { of the lowest rib cage } \\
\text { and the iliac crest }\end{array}$ & $\begin{array}{l}102 \mathrm{~cm} \text { in men and } \\
88 \mathrm{~cm} \text { in women } \\
(90 \mathrm{~cm} \text { in males and } \\
80 \mathrm{~cm} \text { in females in } \\
\text { Asians) is high risk }\end{array}$ \\
\hline 4 & $\begin{array}{l}\text { Waist-hip } \\
\text { ratio }\end{array}$ & $\begin{array}{l}\text { Ratio of waist } \\
\text { circumference and the } \\
\text { hip circumference }\end{array}$ & $\begin{array}{l}1 \text { for men and } 0.85 \text { for } \\
\text { women }\end{array}$ \\
\hline
\end{tabular}

management of weight gain, as well as preventive aspects, in patients with SMI. The review is divided into five sections: in the first part, we examine the drugs implicated in weight gain in patients with SMl; next, we provide an overview of the monitoring frequency of metabolic parameters in this group; then, we discuss general principles of the weight management in SMI; this is followed by a section on lifestyle interventions that are considered the first line for weight gain in SMI; and finally, we end by discussing the evidence-based pharmacological interventions for the issue. The review is practically focused so as to aid clinical practice.

\section{Drugs Causing Weight Gain}

Several classes of psychotropic medications are associated with weight gain, including antipsychotics, antidepressants, and mood stabilizers.

\section{Antipsychotics}

Atypical antipsychotics are considered responsible for the metabolic adverse effects, including weight gain, with clozapine and olanzapine having the highest risk. Among mid-risk groups are amisulpride, asenapine, iloperidone, paliperidone, quetiapine, risperidone, and sertindole, whereas aripiprazole, lurasidone, and ziprasidone have the lowest risk. ${ }^{17}$ However, given prolonged exposure (which is common for SMIs), almost all antipsychotics, including typical antipsychotics, are associated with weight gain. Weight gain is more pronounced in antipsychotic-naive patients and adolescents; thus those receiving treatment for the first episode of psychosis are at a higher risk. ${ }^{18}$ There is a possibility that those gaining weight with antipsychotics show a good response to treatment, i.e. a metabolic threshold, similar to the concept of neuroleptic threshold. ${ }^{19}$

\section{Antidepressants}

There is a significant increase in the incidence of weight gain following antidepressant exposure, i.e. almost $21 \%$ increase over 10 years. ${ }^{20}$ Weight gain is more common with tricyclic antidepressants (e.g. amitriptyline), mirtazapine, and paroxetine and becomes prominent with long-term use. ${ }^{21}$ In contrast, fluoxetine and bupropion are relatively weight-neutral antidepressants.

\section{Mood Stabilizers}

Weight gain is a frequent adverse effect of long-term lithium therapy. ${ }^{22}$ Several anticonvulsant mood stabilizers, including valproate, carbamazepine, and oxcarbazepine, are associated with significant weight gain, specifically with the long-term treatment. ${ }^{23}$

Besides the psychotropics, medications prescribed for treating comorbid medical conditions (e.g. diabetes, hypertension) among those with SMI could also contribute to weight gain. Antidiabetic medications, such as insulin, sulfonylureas, and thiazolidinediones are commonly associated with significant weight gain. ${ }^{24}$ Other medications, including antihypertensives (e.g. beta-blockers) and steroids (e.g. glucocorticoids), are commonly associated with weight gain. ${ }^{25}$

\section{Monitoring/Assessment Frequency in SMI}

The goal of monitoring patients with SMI is to prevent the development of risk factors for CVD. It is recommended that all patients with SMI be routinely monitored for weight gain, glycemic imbalance, dyslipidemia, blood pressure changes, and lifestyle factors, such as diet, smoking, and physical activity. ${ }^{26}$ All patients with SMI must also be provided with adequate nutritional advice and encouragement to promote positive lifestyle changes.

\section{Monitoring Frequency for Weight/BMI}

The weight of all patients with SMI, regardless of whether they are on antipsychotics or not, must be measured at the baseline. Subsequently, for those with normal baseline screening and absence of CVD risk factors, weight must be checked at 6 weeks, 3 months, 12 months, and annually thereafter. Monitoring should be customized to the individual patient; for instance, it is a good practice to record weight and BMI at every visit for those with a higher risk of adverse metabolic effects of the medications. This includes the first episode, drug-naïve patients or adolescents with psychosis. Another dictum is to front-load assessments; in other words, have a greater frequency of monitoring in the first year after antipsychotic initiation when the risk of weight gain with medicines is higher. ${ }^{27}$

\section{Monitoring Frequency for Other Metabolic Risk Factors}

Other key CVD risk factors, such as fasting glucose, lipid profile, and blood pressure, must be monitored at baseline, 6 weeks, 3 months, and quarterly after that. ${ }^{27}$ Again, as explained earlier, monitoring frequencies must be adjusted to suit the individual patient's risk profile. A suggested scheme for monitoring metabolic risk factors in patients with SMI is shown in Table 2.

\section{General Principles of Weight MANAGEMENT IN SMI \\ Dietary Advice}

Evidence suggests that compared to the general population, people with SMI are more likely to follow unhealthy dietary habits. ${ }^{28}$ Therefore, all overweight or obese patients with SMI should receive adequate counseling about healthy dietary habits and nutrition.

\section{Weight Management}

Along with pharmacotherapy for specific metabolic disturbances, advice about weight reduction is intended to help overweight SMI patients to lose weight and is a key component of therapy for the management of metabolic syndrome. Weight reduction, though challenging, can be attained with lifestyle interventions detailed below with beneficial spinoffs on the metabolic risk profile. ${ }^{27}$ 


\begin{tabular}{|c|c|c|c|c|c|c|}
\hline \multirow[b]{3}{*}{ Parameter } & \multicolumn{6}{|c|}{ Frequency of assessment } \\
\hline & \multicolumn{4}{|c|}{ First year of antipsychotic treatment } & \multicolumn{2}{|c|}{ Subsequent monitoring } \\
\hline & Baseline & 6 weeks & 3 months & 12 months & Quarterly & Yearly \\
\hline $\begin{array}{l}\text { Personal and family history of diabetes, } \\
\text { hypertension, CVD }\end{array}$ & $\checkmark$ & & & & & $\checkmark$ \\
\hline $\begin{array}{l}\text { Lifestyle factors (smoking, sedentary } \\
\text { lifestyle, exercise, dietary patterns) }\end{array}$ & $\checkmark$ & $\checkmark$ & $\checkmark$ & & $\checkmark$ & $\checkmark$ \\
\hline Weight, waist circumference, BMI & $\checkmark$ & $\checkmark$ & $\checkmark$ & & $\checkmark$ & \\
\hline Blood pressure & $\checkmark$ & $\checkmark$ & $\checkmark$ & & $\checkmark$ & \\
\hline Fasting glucose & $\checkmark$ & $\checkmark$ & $\checkmark$ & & & $\checkmark$ \\
\hline Fasting lipid profile & $\checkmark$ & & $\checkmark$ & $\checkmark$ & & $\checkmark$ \\
\hline
\end{tabular}

CVD, cardiovascular disease; BMI, body mass index. Source: Adapted from De Hert et al. ${ }^{27}$

\section{Encouragement to Increase Physical Activity}

Aggressive lifestyle modifications and encouragement to increase physical activity occupy a central role in the lifestyle interventions package that is usually tailored to the needs of the individual SMI patient. This ties in with the evidence that people with SMI are more likely to follow sedentary lifestyles with reduced physical activity, placing them at a greater risk of metabolic disorders, such as diabetes and CVD. ${ }^{29}$

\section{Selection of Treatment Strategy (Separately for Drug-naïve Patients and Those Already on FGA/SGA)}

The treatment principles for metabolic risk factors in patients with SMI are broadly similar, regardless of whether they are taking antipsychotics or not. In those who are already on treatment with a first-generation or second-generation antipsychotic (FGA/SGA), the difference is that changes in the treatment regimen should be considered as a first-line strategy, i.e. (a) dose reduction-for those in whom the current clinical status and treatment history permits, clinicians may consider an appropriate dose reduction of antipsychotics under close supervision for symptom relapse and (b) switching antipsychotics-for those with more severe or unacceptable weight gain and dyslipidemia with the ongoing agent, a switch to an antipsychotic agent with better metabolic profile (such as aripiprazole or ziprasidone) is associated with better weight loss and lipid profile outcomes. ${ }^{22,30,31}$

\section{Lifestyle Interventions for Overweight or Obese Patients with SMI}

People with SMI follow lifestyles that put them at a higher risk of obesity and adverse cardiovascular events. ${ }^{32,33}$ The aim of lifestyle interventions in people with SMI is to prevent or attenuate cardiovascular risk factors, such as weight, physical activity, and blood pressure. Needless to say, the package of lifestyle interventions must be tailored to the requirements of the individual patient.

For patients with SMI who are overweight or obese, either lifestyle interventions or medications are possible treatment options with the lifestyle advice preferred as the first-line intervention among those who are willing, motivated, and capable of executing the advice given. The major components of lifestyle interventions for people with SMI are detailed below and summarized in Table 3:

\section{Psychoeducation}

In this context, psychoeducation should emphasize nutritional counseling where adequate education is given about the caloric
Table 3: Components of various lifestyle interventions for overweight or obese patients

\begin{tabular}{ll}
\hline Intervention & Key components/advice \\
\hline Psychoeducation & - Nutritional counseling \\
& - Recommended diet composition \\
& - Healthy snack options \\
Dietary and physical & - Avoid sugar and soft drinks with artificial \\
activity modification & sweeteners \\
& - Limit fast foods and processed foods \\
& - 30 minutes of moderately vigorous \\
& - Inysical activity for most days a week \\
& (e.g. use staircase instead of the elevator) \\
& Set goals that are \\
Learning skills of & - Specific \\
behavior self- & - Measurable \\
management & - Attainable \\
& - Realistic \\
& - Timely \\
Motivational & - Interview with open-ended questions \\
enhancement & - Rffirmative statements \\
& - Summary statements \\
& - Formulating immediate plan of action \\
\hline
\end{tabular}

value of food items that are regularly consumed by the patient. The goal is to help patients to recognize the calorie-dense items that may be inadvertently contributing to their weight problem, for example, aerated soft drinks or fast foods. Patients also benefit from knowing the recommended composition of diet and healthy snack options when they are hungry. Culturally appropriate e-resources that provide this information may be shared with patients.

\section{Dietary and Physical Activity Modification}

Changes in dietary habits can have substantial benefits on weight and other metabolic indices. A 5\% or greater reduction in weight is associated with a reduction in cardiovascular risk and disease. Further, physical activity can improve metabolic indices even in the absence of weight reduction. ${ }^{34}$

Specific suggestions that can be given in this context are (a) avoid juices and soft drinks containing sugar and artificial sweeteners; (b) avoid fat-rich and calorie-dense foods, such as fast or processed foods; (c) choose healthy snack options when there is a need to munch; (d) advice 30 minutes of moderately vigorous 
activity (a brisk walk) for most days a week; and (e) innovative ways to get the daily recommended physical activity, i.e. incorporate exercise into daily routines (e.g. using staircase instead of elevators, parking the car farther away from the entrance) or partnering with an exercise buddy to motivate each other.

\section{Learning Skills of Behavioral Self-management}

Self-management refers to the process by which individuals feel empowered to take active steps in recognizing and managing their health issues on their own, thus taking greater responsibility for their health and recovery. In behavior self-management, the goal is to facilitate goal setting for healthy behaviors and lifestyle changes to reduce the cardiometabolic risk. ${ }^{35}$ The goals that are set must follow the following principles: (a) Specific - this includes defining the goal and how it is intended to be achieved; (b) Measurable-how will the individual know that the goal has been accomplished? (c) Attainable-is the goal attainable for the individual? (d) Realistic - is the goal realistically achievable for the individual? Is the individual willing to work to achieve it? and (e) Timely - is the time frame set for the task motivating enough or is it unrealistic and demotivating?

\section{Motivational Enhancement}

The role of motivational enhancement assumes significance when patients are ambivalent about making the necessary changes in their behavior and lifestyle. Motivational enhancement strategies for lifestyle changes follow the same framework as used for substance use disorders in exploring and resolving ambivalence about behavioral changes. ${ }^{36}$ Brief steps are listed below: (a) Engage the patient by asking for their permission to discuss about their health/smoking/weight issues; (b) Open-ended questions-how do you feel about your smoking/weight? This question allows the patient to express himself/herself; (c) Affirmative statements - this is meant to support positive behaviors. "You have already taken steps to reduce weight. I can see how important this is for you;" (d) Reflection-to allow the patient's concerns to be aired. "You seem to be trying your best to make time for exercise but evidently it has been hard for you to do that. Tell me a bit more about it;" (e) Summary statements-to convey that you have understood the patient correctly and allow patients to come up with next steps of change. "You have evidently taken the issue seriously and have tried a number of things that did not quite seem to work. You seem unsure about what next to do;" (f) Make an immediate plan by discussing next steps- "What would be the next thing that you want to do for your weight problem?" and (g) Close on a positive note by promoting self-efficacy and highlighting change talk- "It is commendable that you have recognized your weight problem and want to do something about it. You are also ready to make changes in your diet and lifestyle choices to meet your goals and have already started implementing them. Let us meet about 2 weeks from now to discuss the progress on this and meanwhile you can try out the steps that we have discussed today."

\section{Pharmacologic Interventions}

Recent evidence on the management of weight gain among subjects who have recently been initiated on antipsychotics suggests possible benefits for more aggressive management with medications. ${ }^{37}$ Pharmacologic interventions may also be useful for patients who are not adequately motivated to change their lifestyles or behaviors. There is preliminary evidence for some agents in promoting weight loss in patients with SMI. These are discussed below:

\section{Metformin}

Metformin has the widest body of evidence for this indication in patients with SMI. A recent meta-analysis of pharmacological interventions for the treatment of weight gain in patients with SMI found 14 trials (pooled $n=864$ ) of which 12 studies (pooled $n=843$ ) yielded data for analysis. The pooled effect size (ES) was$3.27 \mathrm{~kg}$ [95\% confidence interval $(\mathrm{Cl}),-4.49$ to -2.06$]$, supporting metformin. ${ }^{38}$ Lesser evidence is available for the preventive use of metformin; one randomized controlled trial found lower mean weight gain in patients with first-episode schizophrenia initiated on olanzapine plus metformin compared to olanzapine plus placebo over 12 weeks. ${ }^{39}$ It is also useful for weight gain related to other medications, such as lithium. ${ }^{40}$

Common adverse effects of metformin are nausea, diarrhea, vomiting, and abdominal discomfort. Less frequent, but potentially dangerous, adverse effects are hypoglycemia, vitamin B12 deficiency, and lactic acidosis; the last one is usually among patients with congestive heart failure, hypoxia, or sepsis, in whom it is not recommended for use. Metformin should also be avoided in patients with hepatic and renal dysfunction, alcohol use disorder, and pregnant women. Metformin should be dosed initially at $500 \mathrm{mg}$ once a day in the morning and increased by $500 \mathrm{mg}$ every week, as tolerated, till $1000 \mathrm{mg}$ twice daily. The higher dosages are associated with greater benefits on weight gain, hence every attempt must be made to reach the maximum tolerated dose. ${ }^{38,41}$

\section{Topiramate}

Six studies (pooled $n=469$ ) have examined the efficacy of topiramate for weight gain in patients with SMI. The pooled ES was $5.33 \mathrm{~kg}(95 \% \mathrm{Cl},-7.20$ to -3.46$)$, favoring topiramate. ${ }^{38}$ Based on the ES reported, topiramate appears to be promising for this indication though, admittedly, only short-term trials ( $<12$ weeks) are available. Common side effects of topiramate are sedation, dizziness, difficulties with cognition, and tingling of hands/feet. Rare, but dangerous, side effects include urolithiasis, metabolic acidosis, secondary angle-closure glaucoma, and hyperammonemia. Suggested dosing is to start with $25 \mathrm{mg}$ at night for a week, increase to $50 \mathrm{mg}$ nightly at week 2 , and then increase by $50 \mathrm{mg}$ every week, as tolerated, till $100 \mathrm{mg}$ twice daily. ${ }^{42}$

\section{Aripiprazole}

A meta-analysis of three clinical trials (pooled $n=266$ ) found benefits for aripiprazole in ameliorating antipsychotic-induced weight gain; the pooled ES was $2.13 \mathrm{~kg}(95 \% \mathrm{Cl}-2.87$ to -1.39$) .{ }^{43}$ The agent has been studied in patients receiving clozapine and experiencing weight gain, with reported side effects, including nausea, anxiety, and akathisia. ${ }^{44}$ The recommended dosing is $5 \mathrm{mg}$ at night for a week and to increase by $5 \mathrm{mg}$ every week, as tolerated, till $15 \mathrm{mg}$ at night.

\section{Liraglutide}

A glucagon-like peptide-1 (GLP-1) receptor agonist, liraglutide has preliminary evidence for the efficacy on weight loss in patients with SMI; a 16-week randomized controlled trial found a decrease of $5.3 \mathrm{~kg}(95 \% \mathrm{Cl}-7.0$ to -3.7$)$ with liraglutide compared to placebo among overweight or obese patients with schizophrenia spectrum disorders. ${ }^{45}$ The agent is commonly associated with nausea and diarrhea and rarely with pancreatitis, ${ }^{46}$ cholecystitis, and cholelithiasis. The recommended starting dose is $0.6 \mathrm{mg}$ subcutaneously every day for a week, $1.2 \mathrm{mg}$ per day for week 2, and then titrate to a target dose of $1.8 \mathrm{mg}$ per day, as tolerated. 
Drug-induced Weight Gain

Table 4: Evidence-based key pharmacologic agents in management of drug-induced weight gain for patients with severe mental illness

\begin{tabular}{|c|c|c|c|}
\hline Agent & Target dose range (daily) & Adverse effects & Monitoring \\
\hline Metformin & $1500-2000 \mathrm{mg}$ & $\begin{array}{l}\text { Common-Nausea, vomiting, diarrhea, abdominal } \\
\text { discomfort } \\
\text { Rare-Headaches, myalgia, low vitamin B12, hypoglycemia }\end{array}$ & $\begin{array}{l}\text { Biannual e-GFR } \\
\text { Annual LFT } \\
\text { Monitor alcohol use }\end{array}$ \\
\hline Topiramate & $100-200 \mathrm{mg}$ & $\begin{array}{l}\text { Common-Paraesthesia, sedation, memory difficulties } \\
\text { Rare-nephrolithiasis/angle-closure glaucoma, metabolic } \\
\text { acidosis }\end{array}$ & $\begin{array}{l}\text { eGFR, LFT, Serum bicarbonate } \\
3 \text { months after starting treatment } \\
\text { and repeat every } 6 \text { months }\end{array}$ \\
\hline Aripiprazole & $15 \mathrm{mg}$ & Akathisia, nausea, anxiety (when taken with clozapine) & For mentioned side effects \\
\hline Liraglutide & $1.8 \mathrm{mg}$ & $\begin{array}{l}\text { Common-nausea, diarrhea, and abdominal discomfort } \\
\text { Rare-pancreatitis, cholelithiasis, and cholecystitis }\end{array}$ & For hypoglycemia \\
\hline Samidorphan & $\begin{array}{l}\text { Fixed dose combination } \\
\text { with olanzapine ( } 10 \mathrm{mg} \\
\text { samidorphan with } \\
5-20 \text { mg olanzapine) }\end{array}$ & Somnolence, increased appetite, and dry mouth & For sedation and dizziness \\
\hline
\end{tabular}

GFR, glomerular filtration rate; LFT, liver function test

\section{Sibutramine}

A total of three studies ( $n=66$ ) examined the efficacy of sibutramine; the pooled ES was $2.86 \mathrm{~kg}(95 \% \mathrm{Cl},-4.72$ to -1.01$)$, favoring sibutramine. ${ }^{38}$ The drug is contraindicated in patients with CVD as in those with hepatic and renal dysfunction. ${ }^{47}$ Concerns about its cardiovascular safety have impacted its use for weight loss, and the drug is no longer available in some countries. ${ }^{48}$

\section{Samidorphan}

Samidorphan is an investigational opioid antagonist with preliminary evidence for ameliorating olanzapine-induced weight gain in a single randomized controlled trial $(n=561)$; adverse effects in the trial were sedation, dry mouth, and increased appetite. ${ }^{49}$ Due to the lack of sufficient evidence, it is not recommended for clinical use yet.

\section{Others with Insufficient Evidence}

Agents with limited or insufficient evidence for weight loss in patients with SMI include orlistat, ${ }^{50}$ L-carnitine, ${ }^{51}$ fluoxetine, ${ }^{52}$ reboxetine, ${ }^{53}$ and naltrexone. ${ }^{54}$

Given the side effect profile of the agents listed above, their use must follow the due process of risk-benefit evaluation for every patient. After initiation, patients should be monitored both for clinical efficacy and adverse effects outlined above. Table 4 lists the pharmacotherapeutic agents that have been studied for weight gain among patients initiated on antipsychotics.

\section{Management of Weight Gain due to Other Causes (Atypical Depression/Sleep Deprivation)}

Other causes of weight gain in patients with SMI include atypical depression ${ }^{55}$ and sleep deprivation. ${ }^{56}$ No specific trials for weight management in these conditions are available. Therefore, the management should be directed at the underlying condition, for instance, management of the depression with pharmacotherapy or other modalities as appropriate and sleep hygiene advice for sleep-related issues. Additionally, dietary counseling and general health promotion advice (such as exercise and physical activity) may be beneficial.

\section{SUMMARY}

Weight gain is common with the treatment of psychiatric disorders with antipsychotics, antidepressants, mood stabilizers, as they require long-term treatment. In addition, the treatment with antidiabetic drugs and corticosteroids for comorbid medical conditions contributes to the risk. Clinical measurement of obesity is important to identify those at risk and monitor them during treatment for early identification and treatment. Simple anthropometric measures, such as body weight, BMI, WC, and WHR, may be routinely incorporated into practice. Psychoeducation and lifestyle modifications, including diet and exercise, should be a part of the treatment of SMls. Choosing relatively weight-neutral drugs (e.g. aripiprazole, bupropion) may be helpful if clinically feasible. The pharmacological treatment for drug-induced weight gain includes metformin, topiramate, aripiprazole, liraglutide, and samidorphan, but the actual weight reduction with these agents is limited.

\section{ORCID}

Samir K Praharaj ㄴ https://orcid.org/0000-0001-8530-1432

\section{References}

1. Tiihonen J, Lönnqvist J, Wahlbeck K, et al. 11-year follow-up of mortality in patients with schizophrenia: a population-based cohort study (FIN11 study). Lancet 2009;374(9690):620-627. DOI: 10.1016/ S0140-6736(09)60742-X.

2. Laursen TM, Nordentoft M, Mortensen PB. Excess early mortality in schizophrenia. Annu Rev Clin Psychol 2014;10:425-448. DOI: 10.1146/ annurev-clinpsy-032813-153657.

3. Jayatilleke N, Hayes RD, Dutta R, et al. Contributions of specific causes of death to lost life expectancy in severe mental illness. Eur Psychiatry 2017;43:109-115. DOI: 10.1016/j.eurpsy.2017.02.487.

4. Rajan TM, Menon V. Psychiatric disorders and obesity: a review of association studies. J Postgrad Med 2017;63(3):182-190. DOI: 10.4103/ jpgm.JPGM_712_16.

5. Mitchell AJ, Vancampfort D, Sweers K, et al. Prevalence of metabolic syndrome and metabolic abnormalities in schizophrenia and related disorders-a systematic review and meta-analysis. Schizophrenia Bulletin 2013;39(2):306-318. DOI: 10.1093/schbul/sbr148.

6. Vancampfort D, Vansteelandt K, Correll CU, et al. Metabolic syndrome and metabolic abnormalities in bipolar disorder: a meta-analysis of prevalence rates and moderators. Am J Psychiatry 2013;170(3): 265-274. DOI: 10.1176/appi.ajp.2012.12050620.

7. Chadda RK, Ramshankar P, Deb KS, et al. Metabolic syndrome in schizophrenia: differences between antipsychotic-naïve and treated patients. J Pharmacol Pharmacother 2013;4(3):176-186. DOI: 10.4103/0976-500X.114596.

8. Ho-Pham LT, Lai TQ, Nguyen MTT, et al. Relationship between body mass index and percent body fat in Vietnamese: implications for the 
diagnosis of obesity. PLoS One 2015;10(5):e0127198. DOI: 10.1371/ journal.pone.0127198.

9. Misra P, Singh AK, Archana S, et al. Relationship between body mass index and percentage of body fat, estimated by bio-electrical impedance among adult females in a rural community of North India: a cross-sectional study. J Postgrad Med 2019;65(3):134-140. DOI: 10.4103/jpgm.JPGM_218_18.

10. Misra A. Ethnic-specific criteria for classification of body mass index: a perspective for Asian Indians and American Diabetes Association position statement. Diabetes Technol Ther 2015;17(9):667-671. DOI: 10.1089/dia.2015.0007.

11. World Health Organization. Obesity, prevention and managing the global epidemic. Report of a WHO consultation on obesity. Geneva: World Health Organization; 1998.

12. Kuriyan R. Body composition techniques. Indian J Med Res 2018;148(5):648-658. DOI: 10.4103/ijmr.IJMR_1777_18.

13. Fang $\mathrm{H}$, Berg $\mathrm{E}$, Cheng $\mathrm{X}$, et al. How to best assess abdominal obesity. Curr Opin Clin Nutr Metab Care 2018;21(5):360-365. DOI: 10.1097/ MCO.0000000000000485.

14. Dent R, Blackmore A, Peterson J, et al. Changes in body weight and psychotropic drugs: a systematic synthesis of the literature. PLoS One 2012;7(6):e36889. DOI: 10.1371/journal.pone.0036889.

15. Shrivastava A, Johnston ME. Weight-gain in psychiatric treatment: risks, implications, and strategies for prevention and management. Mens Sana Monogr 2010;8(1):53-68. DOI: 10.4103/0973-1229.58819.

16. Gracious BL, Meyer AE. Psychotropic-induced weight gain and potential pharmacologic treatment strategies. Psychiatry (Edgmont) 2005;2(1):36-42.

17. Musil R, Obermeier M, Russ $P$, et al. Weight gain and antipsychotics: a drug safety review. Expert Opin Drug Saf 2015;14(1):73-96. DOl: 10.1517/14740338.2015.974549.

18. Bak M, Fransen A, Janssen J, et al. Almost all antipsychotics result in weight gain: a meta-analysis. PLoS One 2014;9(4):e94112. DOI: 10.1371/ journal.pone.0094112.

19. Venkatasubramanian G, Rao NP, Arasappa R, et al. A longitudinal study of relation between side-effects and clinical improvement in schizophrenia: is there a neuro-metabolic threshold for second generation antipsychotics? Clin Psychopharmacol Neurosci 2013;11(1):24-27. DOI: 10.9758/cpn.2013.11.1.24.

20. Gafoor R, Booth HP, Gulliford MC. Antidepressant utilisation and incidence of weight gain during 10 years' follow-up: population based cohort study. BMJ 2018;361:k1951. DOI: 10.1136/bmj.k1951.

21. Serretti A, Mandelli L. Antidepressants and body weight: a comprehensive review and meta-analysis. J Clin Psychiatry 2010;71(10):1259-1272. DOI: 10.4088/JCP.09r05346blu.

22. Baptista T, Kin NMKNY, Beaulieu S, et al. Obesity and related metabolic abnormalities during antipsychotic drug administration: mechanisms, management and research perspectives. Pharmacopsychiatry 2002;35(6):205-219. DOI: 10.1055/s-2002-36391.

23. Schwartz TL, Nihalani N, Jindal S, et al. Psychiatric medication-induced obesity: a review. Obes Rev 2004;5(2):115-121. DOI: 10.1111/j.1467789X.2004.00139.x.

24. McFarlane SI. Antidiabetic medications and weight gain: implications for the practicing physician. Curr Diab Rep 2009;9(3):249-254. DOI: 10.1007/s11892-009-0040-7.

25. Wharton S, Raiber L, Serodio KJ, et al. Medications that cause weight gain and alternatives in Canada: a narrative review. Diabetes Metab Syndr Obes 2018;11:427-438. DOI: 10.2147/DMSO.S171365.

26. Holt RIG. The management of obesity in people with severe mental illness: an unresolved conundrum. Psychother Psychosom 2019;88(6):327-332. DOI: 10.1159/000503835.

27. De Hert M, Cohen D, Bobes J, et al. Physical illness in patients with severe mental disorders. II. Barriers to care, monitoring and treatment guidelines, plus recommendations at the system and individual level. World Psychiatry 2011;10(2):138-151. DOI: 10.1002/j.2051-5545.2011. tb00036.x.

28. Bushe C, Haddad P, Peveler R, et al. The role of lifestyle interventions and weight management in schizophrenia. J Psychopharmacol 2005;19:28-35. DOI: 10.1177/0269881105058682.
29. Bort-Roig J, Briones-Buixassa L, Felez-Nobrega M, et al. Sedentary behaviour associations with health outcomes in people with severe mental illness: a systematic review. Eur J Public Health 2020;30(1): 150-157. DOI: 10.1093/eurpub/ckz016.

30. Stroup TS, McEvoy JP, Ring KD, et al. A randomized trial examining the effectiveness of switching from olanzapine, quetiapine, or risperidone to aripiprazole to reduce metabolic risk: comparison of antipsychotics for metabolic problems (CAMP). Am J Psychiatry 2011;168(9):947-956. DOI: 10.1176/appi.ajp.2011.10111609.

31. American Diabetes Association, American Psychiatric Association, American Association of Clinical Endocrinologists, et al. Consensus development conference on antipsychotic drugs and obesity and diabetes. J Clin Psychiatry 2004;65(2):267-272. DOI: 10.4088/ jcp.v65n0219.

32. McCreadie RG, Scottish Schizophrenia Lifestyle Group. Diet, smoking and cardiovascular risk in people with schizophrenia: descriptive study. Br J Psychiatry 2003;183:534-539. DOI: 10.1192/bjp.183.6.534.

33. Brown S, Birtwistle J, Roe L, et al. The unhealthy lifestyle of people with schizophrenia. Psychol Med 1999;29(3):697-701. DOI: 10.1017/ s0033291798008186.

34. Klein S, Burke LE, Bray GA, et al. Clinical implications of obesity with specific focus on cardiovascular disease: a statement for professionals from the American Heart Association Council on Nutrition, Physical Activity, and Metabolism: endorsed by the American College of Cardiology Foundation. Circulation 2004;110(18):2952-2967. DOI: 10.1161/01.CIR.0000145546.97738.1E.

35. Lean M, Fornells-Ambrojo M, Milton A, et al. Self-management interventions for people with severe mental illness: systematic review and meta-analysis. Br J Psychiatry 2019;214(5):260-268. DOI: 10.1192/ bjp.2019.54.

36. Miller W, Rolinick S. Motivational interviewing: helping people change. New York: Guilford Press; 2013.

37. Vandenberghe F, Gholam-Rezaee M, Saigí-Morgui N, et al. Importance of early weight changes to predict long-term weight gain during psychotropic drug treatment. J Clin Psychiatry 2015;76(11):e1417e1423. DOI: 10.4088/JCP.14m09358.

38. Hiluy JC, Nazar BP, Gonçalves WS, et al. Effectiveness of pharmacologic interventions in the management of weight gain in patients with severe mental illness: a systematic review and meta-analysis. Prim Care Companion CNS Disord 2019;21(6):19r02483. DOI: 10.4088/ PCC.19r02483.

39. Wu R-R, Zhao J-P, Guo X-F, et al. Metformin addition attenuates olanzapine-induced weight gain in drug-naive first-episode schizophrenia patients: a double-blind, placebo-controlled study. Am J Psychiatry 2008;165(3):352-358. DOI: 10.1176/appi. ajp.2007.07010079.

40. Praharaj SK. Metformin for lithium-induced weight gain: a case report. Clin Psychopharmacol Neurosci 2016;14(1):101-103. DOI: 10.9758/ cpn.2016.14.1.101.

41. Praharaj SK, Jana AK, Goyal N, et al. Metformin for olanzapineinduced weight gain: a systematic review and meta-analysis. Br J Clin Pharmacol 2011;71(3):377-382. DOI: 10.1111/j.1365-2125.2010.03783.x.

42. Zhuo C, Xu Y, Liu S, et al. Topiramate and metformin are effective add-on treatments in controlling antipsychotic-induced weight gain: a systematic review and network meta-analysis. Front Pharmacol 2018;9:1393. DOI: 10.3389/fphar.2018.01393.

43. Mizuno Y, Suzuki T, Nakagawa A, et al. Pharmacological strategies to counteract antipsychotic-induced weight gain and metabolic adverse effects in schizophrenia: a systematic review and metaanalysis. Schizophr Bull 2014;40(6):1385-1403. DOI: 10.1093/schbul/ sbu030.

44. Fleischhacker WW, Heikkinen ME, Olié J-P, et al. Effects of adjunctive treatment with aripiprazole on body weight and clinical efficacy in schizophrenia patients treated with clozapine: a randomized, double-blind, placebo-controlled trial. Int J Neuropsychopharmacol 2010;13(8):1115-1125. DOI: 10.1017/S1461145710000490.

45. Larsen JR, Vedtofte L, Jakobsen MSL, et al. Effect of liraglutide treatment on prediabetes and overweight or obesity in clozapine- or olanzapine-treated patients with schizophrenia spectrum disorder: 
a randomized clinical trial. JAMA Psychiatry 2017;74:719-728. DOI: 10.1001/jamapsychiatry.2017.1220.

46. Jeyaraj S, Shetty AS, Kumar CRR, et al. Liraglutide-induced acute pancreatitis. J Assoc Physicians India 2014;62(1):64-66.

47. Perrio MJ, Wilton LV, Shakir SAW. The safety profiles of orlistat and sibutramine: results of prescription-event monitoring studies in England. Obesity 2007;15(11):2712-2722. DOI: 10.1038/oby.2007.323.

48. Li M-F, Cheung BM. Rise and fall of anti-obesity drugs. World J Diabetes 2011;2(2):19-23. DOI: 10.4239/wjd.v2.i2.19.

49. Correll CU, Newcomer JW, Silverman B, et al. Effects of olanzapine combined with samidorphan on weight gain in schizophrenia: a 24-week phase 3 study. Am J Psychiatry 2020;177(12):1168-1178. DOI: 10.1176/appi.ajp.2020.19121279.

50. Joffe G, Takala P, Tchoukhine E, et al. Orlistat in clozapine- or olanzapine-treated patients with overweight or obesity: a 16-week randomized, double-blind, placebo-controlled trial. J Clin Psychiatry 2008;69:706-711. DOI: 10.4088/jcp.v69n0503.

51. Elmslie JL, Porter RJ, Joyce PR, et al. Carnitine does not improve weight loss outcomes in valproate-treated bipolar patients consuming an energy-restricted, low-fat diet. Bipolar Disord 2006;8:503-507. DOI: 10.1111/j.1399-5618.2006.00345.x.
52. Bustillo JR, Lauriello J, Parker K, et al. Treatment of weight gain with fluoxetine in olanzapine-treated schizophrenic outpatients. Neuropsychopharmacology 2003;28:527-529. DOI: 10.1038/ sj.npp.1300089.

53. Dayabandara M, Hanwella R, Ratnatunga S, et al. Antipsychoticassociated weight gain: management strategies and impact on treatment adherence. Neuropsychiatr Dis Treat 2017;13:2231-2241. DOI: 10.2147/NDT.S113099.

54. Tek C, Ratliff J, Reutenauer E, et al. A randomized, double-blind, placebo-controlled pilot study of naltrexone to counteract antipsychotic-associated weight gain: proof of concept. J Clin Psychopharmacol 2014;34(5):608-612. DOI: 10.1097/ JCP.0000000000000192.

55. Lasserre AM, Glaus J, Vandeleur CL, et al. Depression with atypical features and increase in obesity, body mass index, waist circumference, and fat mass: a prospective, populationbased study. JAMA Psychiatry 2014;71(8):880-888. DOI: 10.1001/ jamapsychiatry.2014.411.

56. Kaskie RE, Graziano B, Ferrarelli F. Schizophrenia and sleep disorders: links, risks, and management challenges. Nat Sci Sleep 2017;9: 227-239. DOI: 10.2147/NSS.S121076. 